\title{
Cognitive-behavioral therapy for management of mental health and stress- related disorders: Recent advances in techniques and technologies
}

\author{
Mutsuhiro Nakao ${ }^{1 *}$, Kentaro Shirotsuki $^{2}$ and Nagisa Sugaya ${ }^{3}$
}

\begin{abstract}
Cognitive-behavioral therapy (CBT) helps individuals to eliminate avoidant and safety-seeking behaviors that prevent self-correction of faulty beliefs, thereby facilitating stress management to reduce stress-related disorders and enhance mental health. The present review evaluated the effectiveness of CBT in stressful conditions among clinical and general populations, and identified recent advances in CBT-related techniques. A search of the literature for studies conducted during 1987-2021 identified 345 articles relating to biopsychosocial medicine; 154 (45\%) were review articles, including 14 systemic reviews, and 53 (15\%) were clinical trials including 45 randomized controlled trials. The results of several randomized controlled trials indicated that CBT was effective for a variety of mental problems (e.g., anxiety disorder, attention deficit hypersensitivity disorder, bulimia nervosa, depression, hypochondriasis), physical conditions (e.g., chronic fatigue syndrome, fibromyalgia, irritable bowel syndrome, breast cancer), and behavioral problems (e.g., antisocial behaviors, drug abuse, gambling, overweight, smoking), at least in the short term; more follow-up observations are needed to assess the long-term effects of CBT. Mental and physical problems can likely be managed effectively with online CBT or self-help CBT using a mobile app, but these should be applied with care, considering their cost-effectiveness and applicability to a given population.
\end{abstract}

Keywords: Biopsychosocial approach, Cognitive-behavioral therapy, Stress management

\section{History of cognitive-behavioral therapy (CBT)}

CBT is a type of psychotherapeutic treatment that helps people to identify and change destructive or disturbing thought patterns that have a negative influence on their behavior and emotions [1]. Under stressful conditions, some individuals tend to feel pessimistic and unable to solve problems. CBT promotes more balanced thinking to improve the ability to cope with stress. The origins of CBT can be traced to the application of learning theory

\footnotetext{
* Correspondence: m-nakao@iuhw.ac.jp

${ }^{1}$ Department of Psychosomatic Medicine, School of Medicine, International University of Health and Welfare, 4-3, Kozunomori, Narita-shi, Chiba 286-8686, Japan

Full list of author information is available at the end of the article
}

principles, such as classical and operant conditioning, to clinical problems. So-called "first-wave" behavioral therapy was developed in the 1950s [2]. In the US, Albert Ellis founded rational emotive therapy to help clients modify their irrational thoughts when encountering problematic events, and Aaron Beck employed cognitive therapy for depressed clients using Ellison's model [3]. Behavioral therapy and cognitive therapy were later integrated in terms of theory and practice, leading to the emergence of "second-wave" CBT in the 1960s. The first- and second-wave forms of CBT arose via attempts to develop well-specified and rigorous techniques based on empirically validated basic principles [4]. From the 1960s onward, the dominant psychotherapies worldwide 
have been second-wave forms of CBT. Recently, however, a third-wave form of CBT has attracted increasing attention, leading to new treatment approaches such as acceptance and commitment therapy, dialectical behavior therapy, mindfulness-based cognitive therapy, functional analytic psychotherapy, and extended behavioral activation; other forms may also exist, although this is subject to conjecture [4]. In a field of psychosomatic medicine, it has been reported that cognitive restructuring is effective in improving psychosomatic symptoms [5], exposure therapy is suitable for a variety of anxious disease conditions like panic disorder and agoraphobia [6], and mindfulness reduces stress-related pain in fibromyalgia [7]. Several online and personal computer-based CBT programs have also been developed, with or without the support of clinicians; these can also be accessed by tablets or smartphones [8]. Against this background, this review focused on the effectiveness of CBT with a biopsychosocial approach, and proposed strategies to promote CBT application to both patient and nonpatient populations.

\section{Research on CBT}

Using "CBT "and "biopsychosocial" as PubMed search terms, 345 studies published between January 1987 and May 2021 were identified (Fig. 1); 14 of 154 review articles were systemic reviews, and 45 of 53 clinical trials were randomized controlled trials. Most clinical trials recruited the samples from patient populations in order to assess specific diseases, but some targeted at those from non-patient populations like a working population in order to assessing mind-body conditions relating to sick leave [9]. The use of biopsychosocial approaches to treat chronic pain is shown to be clinically and economically efficacious [10]; for example, CBT is effective for chronic low-back pain [11]. The prevalence of chronic low-back pain, defined as pain lasting for more than 3 months, was reported to be $9 \%$ in primary-care settings and $7-$
$29 \%$ in community settings [12]. Chronic low-back pain is not only prevalent, but is a source of significant physical disability, role impairment, and diminished psychological well-being and quality of life [11]. Interestingly, according to the results of our own study [13], CBT was effective among hypochondriacal patients without chronic low-back pain, but not in hypochondriacal patients with chronic low-back pain. These group differences did not seem to be due to differences in the baseline levels of hypochondriasis. Although evidence has suggested that both hypochondriasis and chronic low-back pain can be treated effectively with CBT [10, $11,14]$, this has not yet been validated. Chronic lowback pain may be associated with a variety of conditions, including anxiety, depression, and somatic disorders such as illness conviction, disease phobia, and bodily preoccupation. The core psychopathology of hypochondriacal chronic low-back pain should be clarified to promote adequate symptom management [13].

Since 2000, Cochrane reviews have evaluated the effectiveness of CBT for a variety of mental, physical, and behavioral problems. Through a search of the Cochrane Library database up to May 2021 [15], 124 disease conditions were assessed to clarify the effects of CBT in randomized controlled trials; the major conditions for which CBT showed efficacy are listed in Table 1. These include a broad range of medical problems such as psychosomatic illnesses (e.g., chronic fatigue syndrome, irritable bowel syndrome, and fibromyalgia), psychiatric disorders (e.g., anxiety, depression, and developmental disability), and socio-behavioral problems (drug abuse, smoking, and problem gambling). For most of these conditions, CBT proved effective in the short term after completion of the randomized controlled trial. Although the number of literature was still limited, some studies have reported significant and long-term treatment effects of CBT on some aspects of mental health like obsessive-compulsive disorder [16] 1 year after the

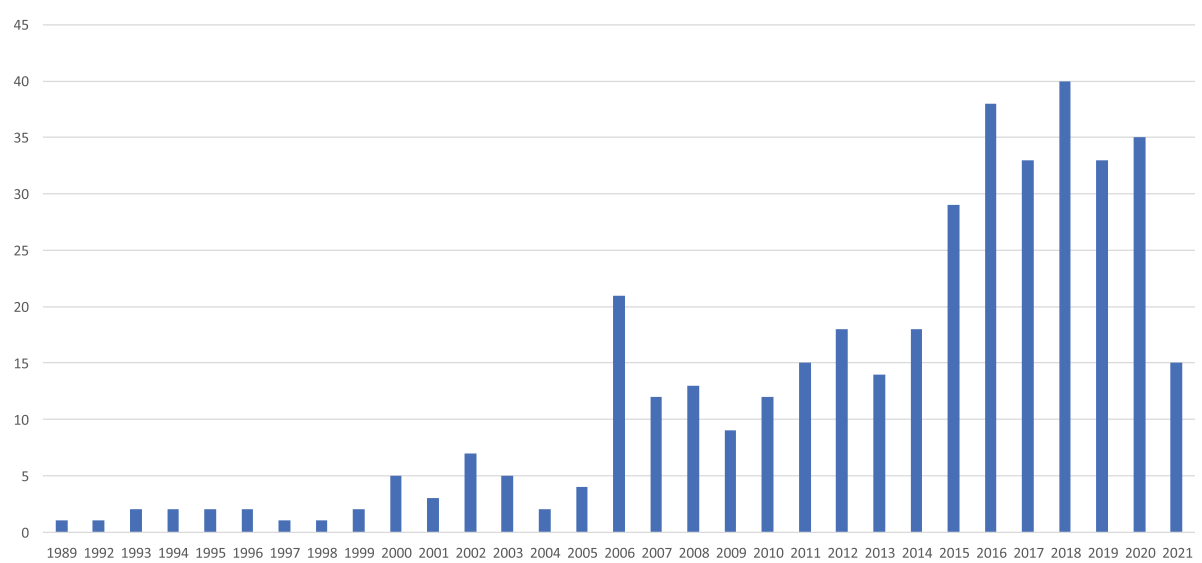

Fig. 1 Number of articles per year identified by a PubMed search from 1989 to the present 
Table 1 Example diseases and problems for which CBT is expected to be effective (Cochrane reviews)

\begin{tabular}{|c|c|c|}
\hline Major disease conditions & Summary of evidence & Update \\
\hline $\begin{array}{l}\text { Psychiatric disorders: } \\
\text { Depression, general }\end{array}$ & $\begin{array}{l}\text { 'Third -wave' CBT as effective treatment of acute depression } \\
\text { Reduced depressive symptoms in dementia and mild cognitive impairment } \\
\text { Improved response and remission rates for treatment-resistant depression } \\
\text { Reduced depressive symptoms in children with long-term physical conditions } \\
\text { Reduced depressive symptoms in chronic obstructive pulmonary disease } \\
\text { Reduced depressive symptoms in dialysis patients } \\
\text { Reduced the number of sickness absence days in workers }\end{array}$ & $\begin{array}{l}\text { October } 2013 \\
\text { January } 2014 \\
\text { May } 2018 \\
\text { December } 2018 \\
\text { March } 2019 \\
\text { December } 2019 \\
\text { October } 2020\end{array}$ \\
\hline $\begin{array}{l}\text { Anxiety, general } \\
\text { Obsessive-compulsive disorder } \\
\text { Panic disorder }\end{array}$ & $\begin{array}{l}\text { Reduced anxiety symptoms in adults by "media-delivered CBT" (self-help) } \\
\text { Reduced anxiety symptoms in dementia and mild cognitive impairment } \\
\text { Reduced anxiety symptoms in adults by therapist-supported internet CBT } \\
\text { Reduced anxiety symptoms in children with long-term physical conditions } \\
\text { Effective for attention control in children and adolescents } \\
\text { Effective in children and adolescents with this disorder } \\
\text { Effective in adults with this disorder } \\
\text { Efficacy of both CBT alone and CBT and antidepressants } \\
\text { Efficacy of both CBT and benzodiazepines }\end{array}$ & $\begin{array}{l}\text { September } 2013 \\
\text { January } 2014 \\
\text { March } 2016 \\
\text { December } 2018 \\
\text { November } 2020 \\
\text { October } 2006 \\
\text { April } 2007 \\
\text { January } 2007 \\
\text { January } 2009\end{array}$ \\
\hline
\end{tabular}

Post-traumatic stress disorder (PTSD) Social anxiety disorder

\section{Acute stress disorder}

Attention deficit-hyperactivity disorder

Bulimia nervosa

Hypochondriasis

Somatoform disorder

Physical diseases:

Breast cancer

Chronic fatigue syndrome

Fibromyalgia

Irritable bowel syndrome

Recurrent abdominal pain

Tinnitus

Behavioral and other problems:

Antisocial behaviors

Benzodiazepine use

Burden of care for dementia

Early behavioral problems

Needle-related problems

Obesity and overweight

Occupational stress

Problem gambling

Self-harm

Sexual abuse

Smoking
Effective in children and adolescents for up to 1 month following CBT Reduced clinician-assessed PTSD symptoms in adults

Reduced PTSD symptoms when used as couple and family therapies Reduced social phobia via brief CBT

Reduced acute traumatic stress symptoms via brief trauma-focused CBT

Beneficial for treating adults with this disorder in the short term

Efficacy of a specific manual-based form of CBT for bulimia nervosa

Reduced hypochondriacal symptoms and general functioning

Reduced symptom severity in adults with somatoform disorders

Improved survival at 12 months (metastatic)

Favorable effects on anxiety, depression and mood disturbance (non-metastatic)

Reduced fatigue symptoms

Reduced pain, negative mood, and disability

Reduced symptoms of irritable bowel syndrome and improved quality of life Reduced pain in the short term in children and adolescents

Reduced negative impacts on quality of life and depression

Reduced antisocial behaviors in young people in the short term Effective in the short term for reducing benzodiazepine harmful use Reduced psychological stress in family caregivers of people with dementia Improved child conduct problems, parental mental health, and parenting skills Reduced children's needle-related pain and distress in children and adolescents Reduced weight, predominantly useful when combined with diet and exercise Reduced stress at work in healthcare workers

Reduced pathological and problem gambling behaviors immediately after CBT Resulted in fewer adults repeatedly self-poisoning and self-injuring

Reduced symptoms of PTSD, anxiety, and depression in children
December 2012

December 2013

December 2019

September 2018

March 2010

March 2018

October 2009

October 2007

November 2014

June 2013

May 2015

July 2008

September 2013

January 2009

January 2017

January 2020

October 2007

May 2015

November 2011

February 2012

October 2018

April 2005

April 2015

November 2012

May 2016

May 2012

January 2012 completion of intervention. Future research should investigate the duration of CBT's effects and ascertain the optimal treatment intensity, including the number of sessions.

\section{Future directions for CBT application in biopsychosocial domains}

In Japan, CBT for mood disorders was first covered under the National Health Insurance (NHI) in 2010, and CBT for the following psychiatric disorders was subsequently added to the NHI scheme: obsessive-compulsive disorder, social anxiety disorder, panic disorder, posttraumatic stress disorder, and bulimia nervosa [17]. The treatment outcomes and health insurance costs for these six disorders should be analyzed as the first step, for appropriate allocation of medical resources according to disease severity and complexity [18]. In Japan, health insurance coverage is provided only when physicians apply for remuneration. A system promoting nurse involvement in CBT delivery [19], as well as shared responsibility between the CBT instructor and certified psychologists (or even a complete shift from physicians to psychologists), has yet to be established. Information and communication technology (ICT) devices may allow CBT delivery to be shared between medical staff and psychologists, in medical, community and self-help 
settings [8]. The journal BioPsychoSocial Medicine published 334 relevant articles up to the end of May 2021, 112 (33.5\%) of which specifically addressed CBT [20]. CBT is a hot topic in biopsychosocial medicine, and more research is required to encourage its application to clinical and general populations.

\section{Abbreviations}

CBT: Cognitive-behavioral therapy; ICT: Information and communication technology; NHI: National Health Insurance; PTSD: Post-traumatic stress disorder

\section{Acknowledgments}

None.

\section{Authors' contributions}

MN organized the project and wrote the entire manuscript. KS and NS conducted the literature search and were involved in the conceptualization of the review. All authors (MN, KS and NS) share final responsibility for the decision to submit the manuscript for publication. The authors read and approved the final manuscript.

\section{Funding}

The study was supported in part by a Research Grant (Kiban C) from the Japanese Ministry of Education, Culture, Sports, Science and Technology.

\section{Availability of data and materials}

Not applicable.

\section{Declarations}

\section{Ethics approval and consent to participate}

Not applicable.

\section{Consent for publication}

All authors have consented to the publication of this manuscript.

\section{Competing interests}

Not applicable.

\section{Author details}

${ }^{1}$ Department of Psychosomatic Medicine, School of Medicine, International University of Health and Welfare, 4-3, Kozunomori, Narita-shi, Chiba 286-8686, Japan. ${ }^{2}$ Graduate School of Human and Social Sciences, Musashino University, Tokyo, Japan. ${ }^{3}$ Unit of Public Health and Preventive Medicine, School of Medicine, Yokohama City University, Yokohama, Japan.

Received: 22 July 2021 Accepted: 24 September 2021

Published online: 03 October 2021

\section{References}

1. Hofmann SG, Asnaani A, Vonk IJ, Sawyer AT, Fang A. The efficacy of cognitive behavioral therapy: a review of meta-analyses. Cognit Ther Res. 2012;36:427-40

2. Blackwell SE, Heidenreich T. Cognitive behavior therapy at the crossroads. Int J Cogn Ther. 2021;8:1-22.

3. Beck AT. Cognitive therapy. A 30-year retrospective. Am Psychol. 1991;46: 368-75.

4. Soler AF, Cebolla A, McCracken LM, D'Amico F, Knapp M, López-Montoyo A, et al. Economic impact of third-wave cognitive behavioral therapies: a systematic review and quality assessment of economic evaluations in randomized controlled trials. Behav Ther. 2018:49:124-47.

5. Hellman CJ, Budd M, Borysenko J, McClelland DC, Benson H. A study of the effectiveness of two group behavioral medicine interventions for patients with psychosomatic complaints. Behav Med. 1990;16:165-73.

6. Wendt J, Hamm AO, Pané-Farré CA, Thayer JF, Gerlach A, Gloster AT, et al. Pretreatment cardiac vagal tone predicts dropout from and residual symptoms after exposure therapy in patients with panic disorder and agoraphobia. Psychother Psychosom. 2018;87:187-9.
7. Schmidt S, Grossman P, Schwarzer B, Jena S, Naumann J, Walach H. Treating fibromyalgia with mindfulness-based stress reduction: results from a 3armed randomized controlled trial. Pain. 2011;152:361-9.

8. Shirotsuki K, Nonaka Y, Takano J, Abe K, Adachi SI, Adachi S, et al. Brief internet-based cognitive behavior therapy program with a supplement drink improved anxiety and somatic symptoms in Japanese workers. Biopsychosoc Med. 2017;11:25

9. Beck BD, Hansen AM, Gold C. Coping with work-related stress through guided imagery and music: randomized controlled trial. J Music Ther. 2015; 52:323-52.

10. Cheatle MD. Biopsychosocial approach to assessing and managing patients with chronic pain. Med Clin North Am. 2016;100:43-53.

11. Cherkin DC, Sherman KJ, Balderson BH, Cook AJ, Anderson ML, Hawkes RJ, et al. Effect of mindfulness-based stress reduction vs cognitive behavioral therapy or usual care on back pain and functional limitations in adults with chronic low back pain: a randomized clinical trial. JAMA. 2016;315:1240-9.

12. Verhaak PF, Kerssens JJ, Dekker J, Sorbi MJ, Bensing JM. Prevalence of chronic benign pain disorder among adults: a review of the literature. Pain. 1998:77:231-9.

13. Nakao M, Shinozaki Y, Nolido N, Ahern DK, Barsky AJ. Responsiveness of hypochondriacal patients with chronic low-back pain to cognitivebehavioral therapy. Psychosomatics. 2012;53:139-47.

14. Barsky AJ, Ahern DK. Cognitive-behavior therapy for hypochondriasis: a randomized controlled trial. JAMA. 2004;291:1464-70.

15. Cochrane library. Cochrane reviews. [https://www.cochranelibrary.com/] Accessed 15 June 2021.

16. Cludius B, Landmann S, Rose N, Heidenreich T, Hottenrott B, Schröder J, et al. Long-term effects of mindfulness-based cognitive therapy in patients with obsessive-compulsive disorder and residual symptoms after cognitive behavioral therapy: twelve-month follow-up of a randomized controlled trial. Psychiatry Res. 2020;291:113-9.

17. Ono Y, Furukawa TA, Shimizu E, Okamoto Y, Nakagawa A, Fujisawa D, et al. Current status of research on cognitive therapy/cognitive behavior therapy in Japan. Psychiatry Clin Neurosci. 2011;65:121-9.

18. Wu Q, Li J, Parrott S, López-López JA, Davies SR, Caldwell DM, et al. Costeffectiveness of different formats for delivery of cognitive behavioral therapy for depression: a systematic review based economic model. Value Health. 2020;23:1662-70

19. Yoshinaga N, Nosaki A, Hayashi Y, Tanoue H, Shimizu E, Kunikata H, et al. Cognitive behavioral therapy in psychiatric nursing in Japan. Nurs Res Pract. 2015;2015:529107.

20. Nakao M, Komaki G, Yoshiuchi K, Deter HC, Fukudo S. Biopsychosocial medicine research trends: connecting clinical medicine, psychology, and public health. Biopsychosoc Med. 2020;14(1):30.

\section{Publisher's Note}

Springer Nature remains neutral with regard to jurisdictional claims in published maps and institutional affiliations.

\section{Ready to submit your research? Choose BMC and benefit from:}

- fast, convenient online submission

- thorough peer review by experienced researchers in your field

- rapid publication on acceptance

- support for research data, including large and complex data types

- gold Open Access which fosters wider collaboration and increased citations

- maximum visibility for your research: over $100 \mathrm{M}$ website views per year

At BMC, research is always in progress.

Learn more biomedcentral.com/submissions 